\title{
2 Cohabitation and the law: myths, money and the media
}

\author{
Anne Barlow, Carole Burgoyne, Elizabeth Clery \\ and Janet Smithson
}

The 2000 British Social Attitudes survey confirmed a growing social acceptance of heterosexual cohabitation as a partnering and parenting choice and identified strong public support for reform of cohabitation law (Barlow et al., 2001). It also established the existence of a 'common law marriage' myth whereby the majority of the public, and cohabitants in particular, falsely believe that cohabiting couples who have lived together for some time have the same legal rights as married couples (Barlow et al., 2001). Even among those cohabitants who were aware of their vulnerable legal position, it was found that very few had taken appropriate steps to gain or provide legal protection despite, as we found in subsequent research, often having good intentions to do so (Barlow et al., 2005).

These findings prompted widespread media interest and government concern. This led the Department for Constitutional Affairs (now the Ministry of Justice) to fund their 2004 Living Together Campaign, aimed at advising cohabitants about their legal rights and indicating practical steps they could take to gain marriage-like protection where possible. ${ }^{1}$ Subsequently, in 2005, with Scotland having already decided to reform the law relating to cohabiting couples (see Family Law (Scotland) Act 2006), the government decided to refer the issue of whether cohabitation law should be reformed to the Law Commission for England and Wales, a decision which sparked further media interest.

The attention paid to cohabitation over the last few years makes it worth revisiting the subject, to see whether, and how, behaviour and attitudes are changing. ${ }^{2}$ So our first aim in this chapter is to examine the evolving prevalence and role of cohabitation as a relationship form in British society. Our second aim is to establish whether attitudes to cohabitation have changed, and whether legal knowledge and actions have increased following a period of sustained

\footnotetext{
* Anne Barlow is Professor of Family Law and Policy, Carole Burgoyne is a Senior Lecturer in the School of Psychology, both at the University of Exeter. Elizabeth Clery is a Senior Researcher at the National Centre for Social Research and is CoDirector of the British Social Attitudes survey series. Janet Smithson is a Research Fellow in the Schools of Law and Psychology at the University of Exeter.
} 
government and media focus. Finally, we consider public beliefs about cohabitants' legal rights and financial practices. This latter issue is vital, as the courts may now take into account how cohabiting couples manage their money in deciding appropriate legal remedies on separation. Some of our key findings have already informed the deliberations of the Law Commission, due to report to Parliament in 2007, but this is the first full account of our research. ${ }^{3}$

\section{Who cohabits, and for how long?}

Certainly, we have not detected any decline in the popularity of cohabitation as a partnering choice. On the contrary, more than one third (36 per cent) of the public have been in a cohabiting relationship at some point, with more than a tenth (11 per cent) currently cohabiting. This represents a slight but statistically significant increase in experience of this form of relationship since 2000, when 33 per cent had cohabited (and nine per cent were currently doing so). It also reflects the gradual long-term increase in the proportion of the public currently cohabiting, identified through analysis of demographic data (Haskey, 2001).

There are a number of possible explanations as to why cohabiting is gradually increasing. These are not mutually exclusive. Attitudes to relationships may be shifting in favour of cohabitation, making this a viable option for sections of the population who would not previously have considered it. Some groups who would previously have got married may now therefore decide to cohabit instead, at least in the short term. Indeed, the cost of a 'proper wedding' has been found in recent research to be a common reason for delaying marriage and engaging in short-term cohabitation (Barlow et al., 2005). Alternatively, or additionally, we may be seeing a generational effect, with cohabiting becoming more common as younger generations, who are known to be more likely to cohabit, gradually replace older ones. Or it may be that the intended purposes of cohabiting relationships are changing, resulting in them being engaged in more widely and over longer periods.

Our evidence does indeed suggest that cohabitation has increased slightly in popularity as a relationship form, and that this increase has taken place at the expense of marriage. Firstly, there is no evidence that people are becoming less keen on relationship forms that involve living with a partner (whether in the form of marriage or cohabitation). Overall, two-thirds of our respondents (65 per cent) fell into this category in 2006, the same proportion as we found in 2000. Secondly, there has been a small but significant decline in the proportion of married people over the same period, from 56 per cent to 54 per cent, and an increase in the proportion who cohabit from nine per cent to 11 per cent.

We turn now to examine the characteristics of those who cohabit and those who marry. Clearly, these groups are not mutually exclusive. Cohabitation and marriage may be engaged in by the same individuals at different life-stages, on more than one occasion and in different sequences. For instance, 31 per cent of cohabitants in 2006 had been married previously and 27 per cent of those who 
are married had previously cohabited. It is notable that trends in the movement between cohabitation and marriage reflect the gradual rise in the former and decline in the latter relationship form. Thus, the proportion of cohabitants who have previously been married has declined by five percentage points since 2000 (from 36 per cent) and the proportion of the married who have previously cohabited has risen by three percentage points (from 24 per cent in 2000).

Despite the overlaps between those who cohabit and those who marry, in 2000 we found considerable variations in the proportions of particular social groups in these relationship forms. In particular, cohabitants were much more likely to be young, to have no religious faith and to have earnings as their main source of income (as opposed to benefits or a pension). As shown in the next table, these trends persist. Now, more than a quarter aged between 25 and 34 cohabit, compared to a tenth aged between 45 and 54 and just one in twenty-five aged between 55 and 64 . Almost a fifth of those with no religion are currently cohabiting, compared to less than one per cent of those who belong to a nonChristian religion. And the link between main source of income and relationship form also remains - with those whose main income source is earnings or benefits being more than 10 times as likely as those who rely on pensions or another source of income to be cohabiting.

Clearly, the latter difference will to some extent result from the fact that an individual's main source of income is strongly linked to their age, with younger respondents (who are much more likely to cohabit) being more likely to rely on earnings or benefits. As there is no obvious theoretical reason for these differences, it may be that the main source of income is acting as a proxy for another factor which links to levels of engagement in different relationship forms.

As those in older age groups are much more likely to belong to a religion, it may be that only one factor out of age and religion independently predicts rates of cohabitation and marriage. However, multivariate analysis (presented in Table A.1 in the chapter appendix) indicates that, even when the interaction between age and religion is controlled for, both independently predict whether an individual is currently cohabiting.

As Table 2.1 shows, not all groups are increasing their levels of cohabitation and decreasing their levels of marriage at the same pace. Cohabiting is increasing at a similar rate in all except the very oldest and youngest age groups. This suggests that the gradual increase in cohabiting can be explained by a 'period' effect (where behaviour changes across all age groups at the one time) rather than a 'generational' effect (where cohabiting increases as younger generations, who are more likely to cohabit, gradually replace older ones).

However, with the exception of those defined by age, the social groups amongst whom cohabiting was most prevalent in 2000 have, by 2006, increased their cohabitation rates the most. The cohabitation rates of those belonging to no religion, Catholics and other Christians, which were the highest in 2000, have all increased by three percentage points; conversely, levels of cohabitation among Anglicans and non-Christians, which were the lowest in 2000, have each declined by one percentage point. The same observation applies to different 
income groups. We found that cohabitation was most common in 2000 among those whose main source of income was earnings or benefits; by 2006, cohabitation rates for these two groups had risen by two and four percentage points respectively (while, for those relying on pensions or another main source of income, cohabitation rates have remained constant).

Table 2.1 Changes in levels of cohabiting and marriage, by age, religion and main source of income

\begin{tabular}{lccccc}
\hline $\begin{array}{l}\text { \% cohabiting and } \\
\text { married in 2006 }\end{array}$ & Cohabiting & $\begin{array}{c}\text { Change } \\
\text { since 2000 }\end{array}$ & Married & $\begin{array}{c}\text { Change } \\
\text { since 2000 }\end{array}$ & Base \\
All & 11 & +2 & 54 & -2 & 4290 \\
Age & 11 & 0 & 5 & +1 & 344 \\
18-24 & 26 & +4 & 42 & -2 & 682 \\
$25-34$ & 16 & +4 & 61 & -3 & 850 \\
$35-44$ & 10 & +3 & 69 & -1 & 693 \\
$45-54$ & 4 & +2 & 73 & -5 & 727 \\
$55-64$ & 1 & 0 & 60 & +5 & 989 \\
$65+$ & & & & & \\
Religion & 6 & -1 & 64 & +1 & 1038 \\
Church of England & 11 & +3 & 54 & -1 & 391 \\
Catholic & 8 & +3 & 58 & -1 & 676 \\
Other Christian & $<1$ & -1 & 64 & +8 & 222 \\
Non-Christian & 17 & +3 & 47 & -1 & 1937 \\
No religion & & & & & \\
Income source & 15 & +2 & 59 & -2 & 2556 \\
Earnings & 1 & 0 & 65 & +5 & 1096 \\
Pension & 11 & +4 & 28 & -2 & 433 \\
Benefits & 1 & 0 & 18 & -8 & 164 \\
Other & & & & & \\
\hline
\end{tabular}

Our findings for marriage follow a similar pattern to those observed for cohabitation; that is, an increase in this form of relationship between 2000 and 2006 in those groups among whom marriage is most prevalent (for instance, the older, those with a non-Christian religion and those living on pensions). In most other groups, the proportion that are married has fallen very slightly between 2000 and 2006 or stayed the same.

These findings suggest that, while those who cohabit and those who marry are not two mutually exclusive groups, if these trends continue cohabitants and the married may become increasingly distinct from one another. 
We turn now to consider whether the reasons why people cohabit might be changing. We know that the average age for marriage has been increasing year on year, with the average age at marriage for men being 36 and 33 for women in 2004 as compared with 27 and 25 in $1990 .{ }^{4}$ But are cohabiting relationships being formed less often as a prelude to, and more frequently as a long-term alternative to, conventional marriage? Such a trend, as well as resulting in a reduction in the proportion of the public that are married, would lead to cohabitations lasting longer, meaning a higher proportion of the public would be cohabiting at any one particular time.

Cohabiting relationships are certainly now lasting longer. For current cohabitants, the mean average length of relationship in 2006 is 6.9 years, compared to 6.5 years in $2000 .^{5}$ For cohabitants with children, the mean increases to 8.5 years (with a median of 7 years), which indicates that such relationships cannot merely be dismissed as fleeting and insignificant when compared to marriage. This is particularly important as cohabitants with children are the group where the primary carer potentially stands to lose most legally from not marrying. And, although there has been a small decrease in the proportion of cohabitants who have a child with their partner (from 42 per cent in 2000 to 39 per cent in 2006), more than a quarter of children are now born to cohabiting couples. ${ }^{6}$

We also find evidence of longer relationship duration among former cohabitants - in 2000, previous cohabitations had lasted an average of 4.3 years whereas in 2006 they have lasted an average of 4.6 years. So one explanation for the increased number of cohabiting relationships we found in 2006 is simply that the same numbers of people are involved in cohabiting as before - they are just doing so for longer, meaning that at any single point in time a greater proportion of the public are cohabiting. And the fact that cohabiting relationships are becoming longer may mean that, for a greater proportion, they are being established as a long-term alternative to or, at the very least, an increasingly long prelude to marriage.

Further weight is added to this conclusion by the fact that slightly fewer cohabitants now go on to marry their partners. In 2000, 59 per cent of previous cohabiting relationships ended in marriage; by 2006 this proportion has declined to 56 per cent. So, for an increasing number, cohabitation may be an end in itself - an alternative to marriage. In 2000, we observed that, in some instances, cohabitation might be a refuge for those disillusioned by previous experiences of marriage. Certainly, the tendency for cohabitants to be more likely to have been married previously persists; 31 per cent of current cohabitants have been married before compared to 17 per cent of those who are currently married. Moreover, cohabitants who have been married before tend to have been cohabiting for longer (an average of 8.3 years, compared to 5.9 years for those who have not), giving further support to the conclusion that, for this group at least, cohabitation is indeed a long-term alternative to marriage.

The fact that cohabiting is becoming more common, particularly in distinct social and religious groupings, may additionally be the result of changes in attitudes towards cohabitation and its main alternative - marriage. It certainly 
appears that cohabitation is increasingly considered to be a valid partnering lifestyle choice, one which has taken on many of the functions of marriage, including parenting. So we next turn to examine if and how attitudes towards cohabitation and marriage have changed in recent years, and how these attitudes relate to take-up of these forms of relationship.

\section{Attitudes to marriage and cohabitation}

In order to assess attitudes towards marriage and cohabitation, we asked respondents how far they agreed or disagreed with four different statements about marriage, each focusing on a positive or negative element of this relationship form, as compared (either implicitly or explicitly) with living together. We had asked the same questions in 2000 and, by comparing responses, we can ascertain whether an increase in cohabiting and decline in marriage has been accompanied (and perhaps prompted) by the development of more positive attitudes towards cohabitation and less positive ones towards marriage. The responses obtained in 2000 and 2006 are presented in the next table.

On two measures, there has been little change since 2000. Less than one tenth in both years agreed that "there's no point getting married - it's only a piece of paper", indicating a continued and widespread belief in the functional importance of marriage. Slightly more than one quarter thought that married people made better parents, a similar proportion as in 2000, leaving almost three-quarters rejecting the view that married parenting is necessarily the best.

While significant changes have taken place on the other two measures, these do not both point in the same direction. The proportion who think that marriage is still "the best kind of relationship", while still a majority, has declined slightly from 59 per cent to 54 per cent. But far more dramatically, and moving in the opposite direction, more than two-fifths now agree that "marriage gives couples more financial security than living together", whereas slightly less than half thought this was the case in 2000. It is likely that the widespread publicity in the intervening period regarding the different legal positions of married and cohabiting couples has played a key role in this change. The governmentsponsored Living Together Campaign has since summer 2004 targeted information at the mass media in order to raise public awareness and try and 'debunk' the 'common law marriage' myth. ${ }^{7}$ Other organisations providing advice to families (for example, One plus One and the National Family and Parenting Institute) also drew attention to the legal position of cohabitants on their websites. Moreover, great media interest was generated by the Law Commission's proposals to reform cohabitation law as set out in their consultation paper in May 2006, just before the start of the survey (Law Commission, 2006). Lastly, there has been considerable publicity surrounding the increased level of financial awards made to wives on divorce. As we will see, this has had the effect of widening the gulf between the financial positions 
of married and unmarried couples on relationship breakdown, as the law currently takes quite different approaches to functionally similar couples.

In summary, therefore, heightened government and media focus on the fact that marriage gives couples greater financial security than cohabiting has probably contributed to increased public recognition of this fact, although it should not be forgotten that a sizeable minority are still seemingly unaware of this.

Table 2.2 Attitudes to marriage and cohabitation, 2000 and 2006

\begin{tabular}{lcc}
\hline $\begin{array}{l}\text { \% agree } \\
\begin{array}{l}\text { Married couples make better parents than } \\
\text { unmarried ones }\end{array}\end{array}$ & 2000 & 2806 \\
$\begin{array}{l}\text { Even though it might not work out for some } \\
\text { people, marriage is still the best kind of } \\
\text { relationship }\end{array}$ & 59 & 54 \\
$\begin{array}{l}\text { Marriage gives couples more financial } \\
\text { security than living together }\end{array}$ & 48 & 61 \\
$\begin{array}{l}\text { There is no point getting married - it's only a } \\
\text { piece of paper }\end{array}$ & 9 & 9 \\
\begin{tabular}{l} 
Base \\
\hline
\end{tabular} & 2980 & 2775 \\
\hline
\end{tabular}

How do different groups of people respond to the attitude statements posed? We might expect cohabitants to respond differently to those who are married as both groups have effectively selected one relationship form as their preferred type, at least for the time being. The next table compares the responses of those currently cohabiting and those who are married to the four statements.

In each case, cohabitants and the married have very different attitudes towards the advantages and disadvantages of marriage, as compared to cohabitation. These differences are in the direction we would expect - that is, those who cohabit are less likely than those who are married to have a positive view of marriage, while for those who are married the reverse is true. For instance, twothirds of those who are married agree marriage is the best kind of relationship, compared to just one quarter of cohabitants. And, while only minorities of any group think marriage is "only a piece of paper", cohabitants are almost five times more likely to do so than those who are married. Those who are married are also substantially more aware of the fact that marriage gives couples more financial security than living together - almost two-thirds agree this is the case, compared to slightly less than half of cohabitants. Of course, awareness of the lack of financial security associated with cohabiting may be one of the factors that prompts people to get married. What is perhaps more surprising is the fact that more than two-fifths of cohabitants are aware that marriage gives couples more financial security, yet have still apparently chosen to cohabit. Of course, it 
may be that they have taken steps to address this situation within their cohabiting relationships, a possibility that the next section explores in detail.

Table 2.3 Attitudes to marriage and cohabitation, by marital status

\begin{tabular}{lccc}
\hline $\begin{array}{l}\text { \% agree } \\
\begin{array}{l}\text { Married couples make better parents } \\
\text { than unmarried ones }\end{array}\end{array}$ & All & Cohabitants & Married \\
$\begin{array}{l}\text { Even though it might not work out for } \\
\text { some people, marriage is still the best } \\
\text { kind of relationship }\end{array}$ & 54 & 28 & 32 \\
$\begin{array}{l}\text { Marriage gives couples more financial } \\
\text { security than living together }\end{array}$ & 61 & 45 & 66 \\
$\begin{array}{l}\text { There is no point getting married - it's } \\
\text { only a piece of paper }\end{array}$ & 9 & 19 & 4 \\
\begin{tabular}{l} 
Base \\
\hline
\end{tabular} & 2775 & 269 & 1343 \\
\hline
\end{tabular}

We know from qualitative studies that many couples see cohabitation as a step towards marriage whilst a minority view is that cohabitation is a preferable alternative for ideological or practical reasons (Barlow et al., 2005, 2007). Some cohabitants might recognise the benefits of marriage and treat short-term cohabitation as a form of 'engagement', with marriage being their ultimate goal, whilst others have actively rejected marriage. This might go some way towards explaining why those with particularly negative attitudes towards marriage tend to have cohabited for longer. Just seven per cent of those who have cohabited for less than three years think marriage is "only a piece of paper", compared to 15 per cent of those who have cohabited for between three and six years and 21 per cent of those who have cohabited for more than seven years. This pattern is replicated across cohabitants' responses to all four statements. Perhaps longterm cohabitants are more likely to have rejected marriage altogether or over time have formed the view that marriage differs little from long-term cohabitation in what it offers.

To what extent are attitudes linked to behaviour? To examine this, we repeated the multivariate analysis described earlier, adding in responses to the four marriage statements shown in Table 2.2. This allows us to assess whether these attitudes independently predict whether an individual is currently cohabiting, once we take account of age and religion. The results of this analysis are presented in the chapter appendix. While age and religion continue to independently predict whether an individual is cohabiting, attitudes also appear to make a difference (although we must remember, of course, that people's attitudes are sometimes a consequence of their choices, rather than a cause). In our model, the belief that married couples make better parents than unmarried 
ones and the view that marriage is "only a piece of paper" were both significant predictors of whether or not a person currently cohabits. ${ }^{8}$

So far, then, we have seen that cohabitation remains an important and increasingly popular family form, although marriage continues to be more prevalent. More couples are cohabiting and these relationships (particularly those of cohabiting parents) are lasting longer. Attitudes to marriage as compared with cohabitation remain broadly similar, although there does seem to be a growing awareness of the fact that marriage provides greater financial security.

\section{Beliefs about cohabitation and money management}

The style of money management adopted by cohabiting couples has recently gained significance in the context of legal reform, both as a possible indicator of commitment within a relationship, and as being relevant to the appropriate legal remedies that should apply on relationship breakdown or death of a partner. Thus, a recent House of Lords decision used the fact that the couple had not merged their finances as evidence that the couple were not operating as a single financial entity. ${ }^{9}$ This was contrasted with the pattern of management more typical of married couples, where the most common form of money management is the joint pool (Pahl, 1995).

So we turn now to consider how the public think cohabiting couples with children should behave financially during their relationship, and how views about this compare with those held about married couples. Do, for instance, people believe that a cohabiting couple with children should treat their finances as if they were two separate individuals, or in the more collective manner associated with marriage? We focus on this in the expectation that our findings will provide important insights into the extent to which marriage and cohabiting are seen as functionally equivalent relationships.

To address these issues, we presented respondents with the following scenario:

Imagine an unmarried couple living together with young children. Both the man and woman work part-time, but he earns more. They share the childcare between them. Which of the options... do you think is the best way for them to organise their money as a couple?

We asked respondents to choose from a number of different options. These included approaches which involve pooling all income together, found previously to be the most common financial practice among married couples (Pahl, 1995). More recently we have witnessed an increase in the use of partial pooling and independent management of finances, especially amongst younger married and unmarried couples (Burgoyne et al., 2006, 2007; Ashby and Burgoyne, 2007). So we also included options that allowed people to express a preference for these approaches instead. We also allowed respondents to 
indicate whether contributions to the household finances should be equal or unequal, depending on income, as these more nuanced aspects of money management have been found to be important in recent research (Ashby and Burgoyne, 2007). The full range of options offered to respondents is shown below, with our shorthand label for each option shown in brackets:

They pool some of their income, with each giving the same amount, and keep the rest of their income separate (partial pooling - equal contributions)

They pool some of their income, with the man giving more, and keep the rest of their income separate (partial pooling - higher earner more)

They keep their incomes separate and deal with bills when they come in, with each paying the same amount (independent management equal contribution)

They keep their incomes separate and deal with bills when they come in, with the man paying more (independent management - higher earner more)

\section{They pool all their income together (pooling)}

\section{Some other arrangement}

Of the six options, just over half (53 per cent) think the couple should pool all of their income (Table 2.4). The second most popular option, favoured by 17 per cent, is partial pooling, with the man contributing more. Since the man in this scenario is depicted as the higher earner, this arrangement helps to offset the disparity in partners' earnings, though, of course, it leaves the precise degree of adjustment unspecified. Partial pooling with equal contributions is slightly less popular and was chosen by 14 per cent of respondents. There is far less support for either form of independent management. These findings serve to underline the strength of the norm of sharing in families, especially when there are dependent children (Sonnenberg et al., 2005). It seems that even when a couple are not married, the idealized view is that money should be pooled to a greater or lesser degree and used as a joint resource, regardless of financial contribution.

There are some differences of opinion between different social groups (though notably men and women do not have different views on this matter). There is less support for pooling all income among the young (particularly those aged 18 to 24). Total pooling of income is favoured by a third (34 per cent) of 18 to 24 year olds and 45 per cent of 25 to 34 year olds. Support for pooling increases for each older age group, with the exception of the over $65 \mathrm{~s}$ where it declines slightly to 55 per cent. These patterns reflect the recent trend towards greater 
separation in finances amongst younger couples, many of whom will have two independent incomes and, certainly among the 18 to 24 year olds, will be less likely to have dependent children.

As Table 2.4 shows, cohabitants are less inclined than the general public to endorse the pooling of all household income, with 48 per cent favouring this compared to 53 per cent of the public as a whole. There may be two possible explanations for this. Firstly, the average age of cohabitants is lower than that for the sample as a whole, and total pooling is less popular in the under $35 \mathrm{~s}$. Secondly, cohabitants who are conscious that they have different rights to married couples, and who have chosen cohabitation deliberately, may be less willing to endorse pooling in the absence of additional safeguards.

Table 2.4 Attitudes to money management for a cohabiting couple with children, by cohabitation status

\begin{tabular}{lcc}
\hline & All & Cohabitants \\
& $\%$ & $\%$ \\
Pooling & 53 & 48 \\
Partial pooling - higher earner more & 17 & 19 \\
Partial pooling - equal contributions & 14 & 13 \\
Independent management - equal contribution & 7 & 9 \\
Independent management - higher earner more & 6 & 8 \\
Some other arrangement & 1 & 1 \\
Don't know & 2 & 1 \\
Base & 2909 & 267
\end{tabular}

How do these findings compare with what cohabitants actually do in practice? Previous research (Vogler et al., 2007) shows that childless cohabitants are more likely than married couples to use one of the more independent systems such as partial pooling or independent management, though these authors also found that 40 per cent of the childless cohabitants in their sample were using the 'joint pool'. However, cohabiting parents were much more similar to married parents, with 52 per cent and 59 per cent respectively using a joint pool approach.

Our findings suggest that a majority of people believe that pooling income (whether fully or partially) is the most appropriate financial arrangement for cohabiting couples with children. This mirrors behaviour among both cohabiting and married parents, and lends support to the view that the public view these two forms of relationship as functionally very similar to one another. We next turn to consider how these two forms of relationships are treated by the law and how the public believe they are treated. 


\section{Cohabitants and the law}

We begin by considering the current legal status of cohabitants in England and Wales, and examine the prevalence of the 'common law marriage' myth. We then examine the legal actions taken by those who are currently cohabiting.

In Scotland, the recent Family Law (Scotland) Act 2006 has given cohabitants cohesive marriage-like remedies on relationship breakdown, and has provided new remedies on death of a cohabitant partner. In England and Wales, the law has developed ad hoc and is yet to adopt a consistent approach to the treatment of cohabiting couples (see Barlow and James, 2004). ${ }^{10}$ At present, cohabitants in England and Wales are treated as if they were married in some situations. Examples of this would include the claiming of means-tested benefits or tax credits, and the transferring of, or succeeding to, the rented tenancy of the family home on relationship breakdown or death. In other situations, the law gives cohabitants rights that are similar to those that apply to people who are married but are usually less generous from the perspective of the financially weaker partner. Examples here would include claiming an inheritance from a partner's estate where that partner has died without making a will under the Inheritance (Provision for Families and Dependants) Act 1975. In yet other situations cohabitants are treated as quite separate and unconnected individuals. Examples would include inheritance tax from which property transfers between spouses are exempt, or claiming a state retirement or widowed person's pension on their partner's national insurance contributions. Perhaps the starkest difference between married and cohabiting couples, however, is on relationship breakdown. Rented tenancies of the family home aside, there is no divorce equivalent for cohabitants, who are dependent on strict and complex property law rather than family law based on principles of 'fairness' to resolve their disputes concerning the owner-occupied family home or other property. As previously observed, this situation has become more anomalous due to the more generous financial provision available to the weaker financial spouse on divorce. Indeed, the gulf between the legal treatment of these two functionally equivalent family forms is one that has widened considerably even since the 2000 British Social Attitudes survey and has received a good deal of media coverage. ${ }^{11}$

\section{The 'common law marriage' myth}

Data from the 2000 British Social Attitudes survey highlighted the fact that, in the broadest terms, the legal position of cohabitants outlined above is not widely understood. Over half, 56 per cent, of the public thought there was such a thing as common law marriage, whereby unmarried couples who have lived together for some time have the same legal rights as married couples. Moreover, this figure could not simply be explained by the fact only a minority of the public were cohabiting; almost six in ten (59 per cent) of those cohabiting in 2000 believed in common law marriage. 
As we have noted, there has been a concerted effort by government, accompanied by intense media coverage, to publicise the disparity in the legal rights and treatment of cohabitants as compared with married couples. Given these activities, we asked respondents to the 2006 survey the same question about common law marriage to see if and to what extent public understanding of the legal position of cohabitants has improved. Specifically, we asked respondents:

As far as you know do unmarried couples who live together for some time have a 'common law marriage' which gives them the same legal rights as married couples?

The responses obtained are presented in the next table. They suggest that only a limited inroad has been made into the myth. True, there has been a slight though significant decline of five percentage points in the proportion who believe that common law marriage "definitely" or "probably" exists; around half now believe this is the case. However, this decline cannot be explained by a rise in the public's knowledge of the legal position of cohabitants. Rather, as often happens when an issue has received extensive publicity, there has been an increase in public uncertainty, with the proportion who could not choose an answer rising from six per cent to 10 per cent. As a result, the proportion who (correctly) answered that common law marriage does not exist has remained almost identical between 2000 and 2006 (at 37 per cent and 38 per cent respectively).

Table 2.5 Belief in existence of common law marriage, 2000 and 2006

\begin{tabular}{lcc}
\hline & $\mathbf{2 0 0 0}$ & $\mathbf{2 0 0 6}$ \\
Belief in existence of common law marriage & $\%$ & $\%$ \\
Definitely do & 17 & 14 \\
Probably do & 39 & 37 \\
Probably do not & 23 & 23 \\
Definitely do not & 14 & 15 \\
Can't choose & 6 & 10 \\
Base & 2669 & 2775 \\
\hline
\end{tabular}

Base: England and Wales only

As much of the publicity around cohabitants' rights has been aimed at cohabitants themselves, it may be that an increase in knowledge has been confined to this group. This is partially true; the proportion of cohabitants who correctly believe that there is no such thing as common law marriage went up from 35 per cent to 39 per cent between 2000 and 2006. While this increase is 
comparatively small and not statistically significant it may indicate that the publicity geared towards cohabitants has, as intended, impacted particularly on the knowledge of this group. However, it is important to note that the same proportion of cohabitants as married people still falsely believe that common law marriage exists (53 per cent in both cases).

Belief in the existence of common law marriage is not equally pervasive across all sections of society. Age is significantly linked, with those in the youngest age group being less likely to believe in its existence, the opposite of what we found in 2000. Forty-four per cent of those aged between 18 and 24 believe common law marriage exists; this lower level of belief can be explained by the fact that almost one fifth (18 per cent) in this group could not choose an answer to the question. It is also notable that belief in common law marriage declines as the level of educational qualifications increases; 39 per cent of graduates believe cohabiting and married couples have the same legal rights, compared to 56 per cent of those with no qualifications. This might reflect a tendency for graduates to be more adept at interpreting the legal position of cohabitants from the range of information available. In contrast to 2000, when men were more likely than women to believe in the existence of common law marriage, we found no difference by gender.

While there has not been a marked increase in public understanding of the legal position of cohabitants, we found earlier that there has been a substantial rise in the proportion of the public who recognise that marriage gives couples more financial security than living together. This security is, of course, itself a consequence of the legal rights associated with the two statuses. So, whilst we cannot conclude that the public has a better understanding of the legal rights of cohabitants than six years ago, there is some evidence that understanding of the impact of these differential rights may have increased.

\section{Taking legal action}

Given that the legal position of cohabitants continues to be poorly understood, we might expect few legal steps to have been taken by cohabitants to address their vulnerable position. Indeed, more than half appear to believe they have the same legal rights as they would have if they were married. What is more, even among those who are aware that legal steps are needed, the assumption that legal knowledge leads to appropriate legal action may not necessarily be correct. The 2000 British Social Attitudes survey and follow-up study identified only a small increase in legal action by cohabitants who were aware of the need for it, with legal costs and an optimism bias (as a consequence of which they believed they were unlikely to split up or die prematurely) being cited as key reasons for inaction (Barlow et al., 2001, 2005). Since 2000, it may be that the increased availability of online legal advice and appropriate legal forms from organisations such as the Living Together Campaign, ${ }^{12}$ as well as publicity about cases where inaction proved ill-advised, has prompted a greater proportion of legally aware cohabitants to take appropriate legal steps. So we 
asked current and previous cohabitants a number of questions about any legal steps which they or their partner had taken with regard to their relationships: whether those who own their accommodation have a written agreement with their partner about their share in the ownership; whether either partner has ever made or changed a will because they were living together or has sought advice about their legal position as a cohabiting couple.

Only a minority of current or previous cohabitants or their partners in 2006 had taken any of these steps. One ninth (11 per cent) of those who own their accommodation had a written agreement about their share in the ownership, a similar proportion (12 per cent) had changed a will as a result of their cohabiting relationship and one fifth (19 per cent) had sought advice about their legal position as a cohabiting couple.

We found no strong evidence that legal actions by cohabitants are increasing, which raises the issue of whether the law's expectation of people taking the 'legally rational' steps available is itself over-optimistic and unlikely to be realised (Barlow and Duncan, 2000; Duncan et al., 2005). For instance, the proportions of previous and current cohabitants who have changed a will as a result of their cohabitation remained almost identical between 2000 and 2006, although this action is slightly (but not significantly) more common among current than among past cohabitants, suggesting that it might be becoming more common over time. We also asked for the first time in 2006 whether cohabitants had sought legal advice about their relationship; however, the proportions of current and previous cohabitants who had done so are identical, suggesting little change over time.

One action has increased in prevalence; that of having a written agreement about each person's share in the ownership of the home. Among current cohabitants where one or both partners own their home, 15 per cent now have such an agreement, up from eight per cent in 2000. This increase is almost certainly due in part to the requirement that declarations of shares in jointly owned property should now be made before a purchase of a home can be registered at the Land Registry. ${ }^{13}$ However, there is no such requirement if just one partner owns the home; any decision to share ownership in these cases would have to be initiated and negotiated between the cohabitants themselves without any prompting, leaving the non-owner legally vulnerable.

Each of the three legal actions we examined are more likely to have been taken by cohabitants in longer relationships. Thus, six per cent of those who have cohabited for less than three years have changed a will as a result of their relationship, compared to 11 per cent and 25 per cent of those who have cohabited for between three and six years and more than seven years respectively.

Are legal actions more likely to be taken by the legally aware minority of cohabitants? While the small size of our samples of cohabitants greatly limits the identification of significant differences, there is certainly some evidence of a link between legal knowledge and legal actions. For instance, of those cohabitants who own their homes, 42 per cent of those with an agreement about their share in the ownership believe the 'common law marriage' myth, 
compared to 51 per cent of those with no agreement. Similarly, those who have sought legal advice about their cohabiting relationships are significantly less likely to believe in common law marriage; this was the case for 43 per cent, compared to 55 per cent of those who had not sought advice. The knowledge that common law marriage does not exist could, of course, have prompted some cohabitants to investigate their legal position, or could have been the consequence of this investigation. It is notable, however, that the levels of knowledge about the legal position of cohabitants are very similar among those who have and have not changed a will as a result of their cohabiting relationship.

Clearly, then, the majority of the public currently believe cohabitants have a far more extensive set of rights than they actually do. This may be because, in the absence of knowledge of the actual legal position, they assume this is what the situation logically should be, given the social acceptance of cohabitation. In addition, the legal steps needed to gain marriage-like protection between cohabitants are not always straightforward, although efforts have been made through government funding and media exposure to make advice and appropriate action more available than was the case previously. Certainly we have found little evidence to suggest that any more than a minority of cohabiting couples have made legal arrangements to protect themselves in the light of relationship breakdown or the death of one partner.

\section{Perceptions of what cohabitants' legal rights should be}

We turn now to examine public views about how the law should treat cohabitants in a variety of situations, irrespective of how it currently operates. Our aim is to examine attitudes to the current law in situations where it treats functionally similar married and cohabiting couples differently and to ascertain what might be publicly acceptable in terms of reform in these areas.

To achieve this, respondents were presented with a number of scenarios describing a range of relationships. For instance, one scenario asked respondents to:

Imagine an unmarried couple who have lived together for 20 years and have three children. The woman had reduced her working to parttime when the first child was born but gave up work entirely after the second child was born in order to care for the family and home. The man has supported the family financially throughout and also owns the family home. The youngest child recently left home and the couple's relationship has now broken down. The woman has no income and poor job prospects.

The scenarios differed in certain key aspects: duration; the presence or absence of children; and the level and types of investment which the two partners had made in the relationship. We asked respondents whether the less well off 
partner in each scenario should have a right to "financial provision" from the better off partner on separation, firstly in situations where the couple had been married and secondly when they had been cohabiting. Currently, in each situation described in the scenarios, the law provides a remedy only for the married. However, the Law Commission is considering what remedies, if any, might be appropriate in cohabiting relationships which are functionally similar to married ones, particularly where one partner suffers financial disadvantage as a result of the relationship.

The responses are presented in Table 2.6. Focusing firstly on those situations involving an unmarried couple, we can see major differences in the proportions of people who think that the less well off partner should be entitled to financial provision. These differences appear to relate to the length of the relationship and how much the less well off partner has invested in it. Thus, when the couple have lived together for 20 years, have three children and the woman gave up work completely to look after the family and home, almost nine-tenths agree she should be entitled to financial provision on separation. However, when the couple have lived together for just two years with one partner having a much higher income and owning the family home (and when no clear investment in the relationship by the less well off partner is indicated), less than four-tenths agree that the less well off partner should have a right to financial provision.

Table 2.6 Attitudes regarding rights to financial provision on separation for married and unmarried couples

\begin{tabular}{|c|c|c|}
\hline $\begin{array}{l}\% \text { agree partner should have right to financial } \\
\text { provision on separation if ... }\end{array}$ & $\begin{array}{l}\text { If couple not } \\
\text { married }\end{array}$ & $\begin{array}{l}\text { If couple } \\
\text { married }\end{array}$ \\
\hline $\begin{array}{l}\text {... couple living together for } 20 \text { years, three children, } \\
\text { woman reduced work to part-time and then gave up } \\
\text { work to look after family and home, man supported } \\
\text { family financially and owns home, woman has no } \\
\text { income and poor job prospects }\end{array}$ & 89 & $\mathrm{n} / \mathrm{a}$ \\
\hline $\begin{array}{l}\text {... couple living together for } 10 \text { years, no children, one } \\
\text { partner worked unpaid to build up other partner's } \\
\text { business, partner who runs business also owns family } \\
\text { home, other partner has no property or income of own }\end{array}$ & 87 & 93 \\
\hline $\begin{array}{l}\text {... couple living together for } 10 \text { years, one partner has } \\
\text { well-paid job requiring frequent moves, other partner } \\
\text { has worked where possible but has not had a settled } \\
\text { career }\end{array}$ & 69 & 81 \\
\hline $\begin{array}{l}\text {... couple living together for two years, one has a much } \\
\text { higher income than the other and owns the family } \\
\text { home }\end{array}$ & 38 & 62 \\
\hline Base & 3197 & 3197 \\
\hline
\end{tabular}

$\mathrm{n} / \mathrm{a}=$ not asked 
We can see a similar level of differentiation when the couple in question are married. While a higher proportion in each scenario think the married partner should have a right to financial provision on separation, as compared to the cohabiting partner, differentiation between the two types of relationship is most marked when its duration and the partners' investments in it are at their lowest. So, for the couple who have lived together for 10 years with one partner working unpaid to build up the other's business, there is a difference of just six percentage points between the proportions who think that the less well off partner should be entitled to financial provision, if married as compared to cohabiting. However, for the couple who have been together two years where one has a much higher income than the other and owns the family home, there is a difference of 34 percentage points, with almost twice as many respondents agreeing the partner should be entitled to financial provision if he or she is married than if he or she is not. Clearly, then, the public's perception of what separating partners should be entitled to is not simply informed by the status of their relationship but relates strongly to its length, as well as the nature and level of the investment in it made by the less well off partner. It could be concluded that when cohabitations become more 'marriage-like', with partners living together for a long time, having children and sharing earning and caring responsibilities between them or prioritising one partner's career, the public are much more likely to feel they should receive the same level of treatment as that given to partners separating from marriage.

The previous questions focused upon financial provision after separation. Of course, some relationships will end because of the death of one of the partners, rather than separation. As we outlined earlier, unless specific measures have been taken, this can leave cohabiting partners vulnerable. To assess what people think should happen in this sort of situation, we asked:

Imagine an unmarried couple without children who have been living together for two years in a house bought in the man's name three years ago, before their relationship began. Say the man died without making a will. Do you think the woman should or should not have the same financial rights regarding his property as she would if she had been married to the man?

In this instance, two-thirds ( 66 per cent) of people think that the woman in the scenario should have the same financial rights she would have done were they married, even though the relationship was short and she has not suffered any apparent financial disadvantage.

These findings show that a majority of the public think that cohabitants should have a far more extensive set of legal rights than they currently do. However, they do not necessarily think cohabitants should have the same rights on separation as married couples - instead they differentiate substantially on the basis of individual circumstances, with the presence or absence of children, 'investment' in the relationship and duration all proving important factors. Clearly, then, it is not just the public understanding of the legal position of 
cohabitants which is at odds with current legislation; so too are public beliefs about what cohabitants' legal position should be.

\section{Conclusions}

What light do our findings shed on the way forward for reform of cohabitation law? Both the strong continued existence of the 'common law marriage' myth and our findings as to what the public think cohabitants' rights should be, lend very strong support for reform of cohabitation law and this has been recognized by the Law Commission (Law Commission, 2007). People are very confused by the disjuncture between the social acceptance of marriage-like cohabitation and its often unmarriage-like legal consequences. Where legal advantage or disadvantage has been gained or suffered by a partner at the expense of another because of their cohabiting relationship, there is strong public support for a legal remedy, with support depending on factors such as the length of the relationship, the presence of children, and the nature of a person's 'investment' in the relationship. The Law Commission's approach to relationship breakdown has public endorsement. The data also reveal a clear case for differentiating between short childless marriages and short childless cohabitations of two years, although it is worthy of note that the case for a claim to financial support after such a marriage has far less endorsement than claims for financial support after longer relationships where economic advantage or disadvantage is demonstrated (as shown in Table 2.6). In the public's mind, the case for a distinction between cohabitation and marriage appears to decrease as the relationships in question lengthen, but a minimum qualification period for such rights of between two and five years as suggested by the Law Commission would seem appropriate. Conversely on death, the data reveal support for a greater generosity than exists currently towards a childless cohabitant of two years standing. Here a majority of two-thirds favour such a cohabitant having the same claim to a deceased partner's property as she would have had if she had been married. Taken with findings from the 2000 British Social Attitudes survey which showed near unanimous support for equal treatment between a childless cohabitant of 10 years standing and a married counterpart, there does seem to be public support for a marriage-equivalent approach consequent upon the cohabitation relationship, rather than one based on proof of economic advantage and disadvantage on death of a cohabitant partner as recommended by the Law Commission (Law Commission, 2007).

Our findings as regards money management issues are also important. Our data show pooling is seen as the ideal when a couple have a child, irrespective of whether a couple are married or cohabiting. This lends some support to the view that the public see these forms of relationship as functionally very similar. However, we would urge caution in placing too much emphasis on this when deciding legal outcomes. Despite the House of Lords decision, some research suggests that financial arrangements cannot and should not always be relied on as a transparent indicator of the nature of an intimate relationship nor of the 
intentions of the two partners (Ashby and Burgoyne, 2007, Douglas et al., 2007). There may be a host of pragmatic reasons for keeping finances separate, such as the need to clear individual debts incurred before the start of the relationship, avoiding the involvement of a current partner in an assessment for maintenance or child support for a previous relationship, or simply inertia and a delay in changing the existing bank accounts. Ashby and Burgoyne found that some couples who appeared to have entirely separate accounts, in practice treated all their money as a collectively owned resource in the same way as is the common practice in marriage.

Overall, our findings confirm that cohabitation is very much here to stay, both as a partnering and a parenting form. However, as the increased duration of cohabiting partnerships makes clear, it is no longer appropriate to regard it is a relatively brief and transitory arrangement (Ermisch and Francesconi, 1999). Cohabitation continues to take on many of the functions of marriage and is seen as a valid lifestyle choice which is socially accepted in virtually all sections of society. Whilst making legal information available to cohabitants is important, there are many people it has not reached. The 'common law marriage' myth lives on, despite the wealth of media exposure the issues have enjoyed in recent years. Perhaps this is because there is no great distinction made by the majority of the public between what the legal remedies available to cohabitants should be as compared to married couples on death or even, in most situations, on relationship breakdown. Where there has been a long-term cohabiting relationship functionally equivalent to marriage, or where there has been a joint enterprise relationship where one partner suffers disadvantage or gains advantage as a consequence of the relationship, there is strong support for legal remedies to be made available. How marriage-like these should be, is at the end of the day, a policy decision for government, but there seems to be little public appetite for the continuation of the deep legal divisions drawn between married and unmarried cohabiting families.

\section{Notes}

1. See http://www.advicenow.org.uk/livingtogether run by the Advicenow organisation and funded by the Department of Constitutional Affairs (now the Ministry of Justice).

2. The British Social Attitudes survey questions on cohabitation reported here are the first phase of a project, funded by the Nuffield Foundation, which goes on in its second phase to further explore issues raised by means of in-depth qualitative research interviews with a purposive sample.

3. The Law Commission's report to Parliament (Law Com. No. 307), which drew upon British Social Attitudes survey data, was published on $31^{\text {st }}$ July 2007.

4. ONS Marriage, Divorce and Adoption Statistics 2004 (Series FM2 No. 32)

5. The median is five years for 2006 and four years for 2000 . 
6. ONS, Birth Statistics Series FM1 No. 33 (2005) Table 3.10 shows that 42 per cent of all live births were to unmarried parents in 2004, with 76.4 per cent of these registrations by couples living at the same address and presumed to be cohabiting.

7. The most intense media publicity took place in May and early June 2006 just before the survey went into the field. The Living Together Campaign featured on BBC Breakfast television, Channel 4 lunchtime news, Radio 5 Live breakfast programme, 33 local radio stations and 5 national newspapers. Following the publication of the Law Commission's consultation paper (Law Commission, 2006) on $31^{\text {st }}$ May 2006, the Living Together Campaign's website was visited 50,000 times over a four day period.

8. As those with a pro-marriage attitude on any particular statement are more likely also to register pro-marriage views on the other three measures, we should exercise caution in concluding that these two specific measures influence individuals' decisions to cohabit.

9. In Stack v. Dowden [2007] UKHL 17 the (unmarried) couple's treatment of money and other assets was taken into account as an indicator of their (non)intention to operate as a single financial entity.

10. Consequently, our subsequent analysis excludes responses from Scotland as the legal position of cohabitants there is quite different from that in England and Wales.

11. For in a recent case, the House of Lords has confirmed that where there are surplus assets, dependent spouses' claims are no longer limited to their reasonable needs even following a short marriage. Rather, all other things being equal, matrimonial asset division is guided by the overarching principle of fairness which is achieved by addressing the parties' needs, compensation for disadvantage caused to one party by the relationship and sharing. It should reflect the fact that marriage is a partnership of equals regardless of who was the breadwinner and who was the homemaker and primary carer of the children (see Miller v. Miller; McFarlane v. McFarlane [2006] UKHL 24).

12. See www.advicenow.org/livingtogether. By the end of May 2006, just less than two years from when the Living Together Campaign was launched, one million Living Together Guides providing free and accessible legal information to cohabitants had been downloaded from their site.

13. See Land Registry documents TR1 and FR1. This was introduced by changes to the Land Registration Rules in 1977 (see SI 1997/3037 rules 19 and 98) and so more cohabitants purchasing a property jointly would have had their attention drawn to this by 2006 than was the case in 2000 .

\section{References}

Ashby, K. and Burgoyne, C. (2007, forthcoming), 'Separate financial entities? Beyond categories of money management', Journal of Socio-Economics 
Barlow, A., Burgoyne, C., and Smithson, J. (2007), The Living Together Campaign An investigation of its impact on legally aware cohabitants, London: Ministry of Justice, available at www.justice.gov.uk/publications/research250707.htm

Barlow, A. and Duncan, S. (2000), 'Family law, moral rationalities and New Labour's communitarianism: Part II', Journal of Social Welfare and Family Law, 22(2): 129-43

Barlow, A., Duncan, S., James, G. and Park, A. (2001) 'Just a piece of paper? Marriage and cohabitation in Britain', in Park, A., Curtice, J., Thomson, K., Jarvis, L. and Bromley, C. (eds.), British Social Attitudes: The $18^{\text {th }}$ Report - Public policy, social ties, London: Sage

Barlow, A., Duncan, S., James, G. and Park, A. (2005), Cohabitation, marriage and the law. Social change and legal reform in 21st Century Britain, Oxford: Hart Publishing

Barlow, A. and James, G. (2004), 'Regulating Marriage and Cohabitation in 21st Century Britain', Modern Law Review, 67(2): 143-176

Burgoyne, C., Clarke, V., Edmunds, A. and Reibstein, J (2006), “'All my worldly goods I share with you?" Managing money at the transition to heterosexual marriage', The Sociological Review, 54: 619-637

Burgoyne, C., Dolman, V., Edmunds, A. and Reibstein, J. (2007), 'Money management systems in early marriage: factors influencing change and stability', Journal of Economic Psychology, 28: 214-228

Douglas, G., Pearce, J., Woodward, H. (2007), A Failure of Trust: Resolving Property Disputes on Cohabitation Breakdown, available at www.law.cf.ac.uk/researchpapers/papers/1.pdf

Duncan, S., Barlow, A. and James, G. (2005), 'Why don't they marry? Cohabitation, commitment and DIY marriage', Child and Family Law Quarterly, 17(3): 383-398

Ermisch J. and Francesconi, M., (1999) 'Cohabitation in Great Britain: Not for long but here to stay', Working Paper of the Institute for Social and Economic Research, Colchester: University of Essex

Haskey, J. (2001) 'Cohabitation in Great Britain: Past, present and future trends - and attitudes', Population Trends 103, available at www.statistics.gov.uk/CCI/article.asp?ID=547\&Pos=7\&ColRank=2\&Rank=144

Law Commission for England and Wales (2006), Cohabitation: The Financial Consequences of Relationship Breakdown (consultation paper 173), London: The Stationery Office

Law Commission for England and Wales (2007), Cohabitation: The Financial Consequences of Relationship Breakdown (Law Commission No. 307), London: The Stationery Office

Pahl, J. (1995), 'His money, her money: Recent research on financial organisation in marriage', Journal of Economic Psychology, 16: 361-376

Sonnenberg, S., Burgoyne, C. and Routh, D. (2005), 'Income disparity and choice of financial organisation in the household', Proceedings, $30^{\text {th }}$ Annual Congress of IAREP, International Association for Research in Economic Psychology: Czech Republic

Vogler, C., Brockmann, M. and Wiggins, R. (2007, forthcoming), 'Managing money in new heterosexual forms of intimate relationships', Journal of Socio-Economics 


\section{Acknowledgements}

The National Centre for Social Research is grateful to the Nuffield Foundation for their financial support which enabled us to ask the questions reported in this chapter from 2006, although the views expressed are those of the authors alone. 


\section{Appendix}

Table A.1 Logistic regression (dependent variable whether respondent currently cohabits) - socio-demographic and attitudinal characteristics

\section{Predictor variables}

Model A

Socio-demographic characteristics

Nagelkerke $R^{2}$

Age (increase by one year)

Religion (no religion)

Church of England

Catholic

Other Christian

Non-Christian

Married couples make better parents than unmarried ones

Decrease in agreement by one unit (agree strongly, agree, neither agree nor disagree, disagree, disagree strongly)

Even though it might not work out for some people, marriage is still the best kind of relationship

Decrease in agreement by one unit (agree strongly, agree, neither agree nor disagree, disagree, disagree strongly)

Marriage gives couples more financial security than living together

Decrease in agreement by one unit (agree strongly, agree, neither agree nor disagree, disagree, disagree strongly)

There is no point getting married - it's only a piece of paper

Decrease in agreement by one unit (agree strongly, agree, neither agree nor disagree, disagree, disagree strongly)

$\begin{array}{ll}0.158 & 0.212 \\ -.053^{* *} & -.044^{\star *} \\ & \\ -.488 & -.148 \\ -.271 & -.131 \\ -.595^{\star *} & -.105 \\ -2.667^{* *} & -1.671^{*}\end{array}$

$.496^{* *}$

* $=$ significant at $5 \%$ level

${ }^{* *}=$ significant at $1 \%$ level 